
About IJMA [last updated July, $\left.1^{\text {st }}, 2021\right]$

$\checkmark$ International Journal of Medical Arts is the Official Journal of the Damietta Faculty of Medicine, AlAzhar University, Egypt

$\checkmark$ It is an International, Open Access, Double-blind, Peer-reviewed Journal

$\checkmark$ Published four times a year

$\checkmark$ The First Issue was published in July 2019

$\checkmark$ Published under the following license: Creative Commons Attribution-ShareAlike 4.0 International Public License (CC BY-SA 4.0). It had updated from the Creative Commons license [CC BY] in volume 2, Issue 4, October 2020 About IJMA

$\checkmark$ The Egyptian Knowledge Bank hosts the web site of IJMA

$\checkmark$ The Egyptian Knowledge Bank supports IJMA

$\checkmark$ IJMA follows the regulations of the International Committee of Medical Journal Editors

$\checkmark$ IJMA is indexed in the "Directory of Open Access Journals" [15 January 2021].

$\checkmark$ IJMA is indexed in JGate [29-6-2021]

$\checkmark$ IJMA is a member of the International Society of Managing and Technical Editors

$\checkmark$ Listed in "Index Copernicus", "Publons", "Academic resource index [ResearchBib]", "Electronics journal library", "Eurasian Scientific Journal Index", and "Citefactor"

$\checkmark$ IJMA introduced to the search engine [BASE] through DOAJ
Click image to reach the page

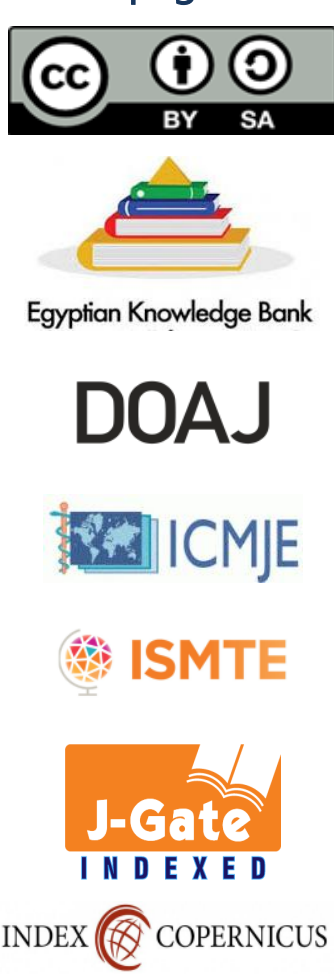

publons

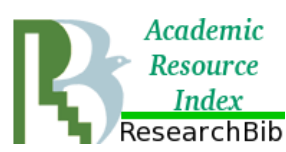

\section{EZ3 \\ .}

ESJII

CiteFactor

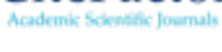

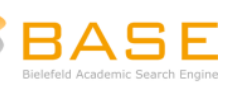




Available online at Journal Website
https://ijma.journals.ekb.eg/
Main subject [Ophthalmology]

Original Article

\title{
Comparison between Foldable and Hard [PMMA] Iris Claw Phakic Intraocular Lens Implantation for Correction of High Myopia
}

\author{
Wael H. Alazab [1]; Abdallah H. Hamed [2]; Younis E. Abdel Hafez [1]; Abdelghany I. Abdelghany [2] \\ 1 Department of Ophthalmology, Damietta Faculty of Medicine, Al-Azhar University, Egypt. \\ ${ }^{2}$ Department of Ophthalmology, Faculty of Medicine, Al-Azhar University, Egypt.
}

Corresponding author: Wael H. Alazab

Email:waelhaggag66@gmail.com

Submission date: March 03, 2021; Acceptance date: August 03, 2021

DOI: $10.21608 / I J M A .2021 .68409 .1284$

DOAJ

\section{ABSTRACT}

Background: Iris claw phakic intraocular lens [PIOL] is one of the surgical techniques used for the correction of high myopia. This procedure reduces myopia with stable refractive results and preserves the accommodation.

Aim of the Work: The aim of this study is to assess the outcome of foldable and hard [PMMA] iris claw PIOL implantation as one of surgical procedures in the management of high myopic young patients.

Patients and Methods: A prospective comparative study having foldable and hard [PMMA] iris claw phakic intraocular lens [PIOL] for correction of high myopia. This study includes forty eyes [40 eyes] of twenty high myopic patients [20 pt.] with refraction range of $[-10.0 \mathrm{D}$ to $-25.0 \mathrm{D}]$ without or with cylinder not more than $[-2.0 \mathrm{D}]$. The patients were divided to two groups $[\mathrm{A}]$ and $[\mathrm{B}]$, each group contains twenty [20] eyes, the first 20 eyes [group A] received a concave-convex foldable iris claw PIOL and the remaining 20 eyes [group $\mathrm{B}$ ] received a biconcave optic hard PMMA iris claw PIOL.

Result: The mean postoperative SE at 6 months in group $[A]$ was $[-0.30 \pm 0.10 \mathrm{D}]$ within $\pm 1.00 \mathrm{D}$ of emmetropia. In group $[\mathrm{B}]$ it was $[-$ $0.50 \pm 0.50 \mathrm{D}]$ within $\pm 1.0 \mathrm{D}$ of emmetropia. The mean postoperative cylinder at 6 months was $[-0.31 \pm 0.10]$ in group $[\mathrm{A}]$, and $[-0.51 \pm 0.51]$ in group $[B]$. There was a statistically significant difference between preoperative UCVA and postoperative UCVA at 6 months were $[p<0.001]$ in both groups. Postoperative BCVA [logMar] at 6 months was $0.11 \pm 0.14$ in group [A] and $0.27 \pm 0.17$ in group $[B]$.

Conclusion: iris-claw phakic IOL implantation is frequently used for highly myopic cases. Compared to corneal refractive surgery, phakic IOLs favorably compete for the correction of high myopia, with increasing predictability, efficacy, safety, and quality of vision.

Keywords: Iris Claw; Foldable; Hard; Phakic.

This is an open-access article registered under the Creative Commons, ShareAlike 4.0 International license [CC BY-SA 4.0] [https://creativecommons.org/licenses/by-sa/4.0/legalcode.

Citation: Alazab WH, Hamed AH, Abdel Hafez YE, Abdelghany Al. Comparison between Foldable and Hard [PMMA] Iris Claw Phakic Intraocular Lens Implantation for Correction of High Myopia. IJMA 2020; 3[3]: July-September:.1741-1747. [DOI: 10.21608/IJMA.2021.68409.1284].

* Main subject and any subcategories have been classified according to the research topic. 


\section{INTRODUCTION}

Fechner and Worst designed in 1986, a new biconcave IOL to correct high myopia, based on the iris claw IOLs employed in cataract surgery. Phakic intraocular lens has several advantages, including excellent refractive results, good quality of vision, stability of refraction, preservation of accommodation, and reversibility [1].

Compared with the clear lens extraction method for treating high myopia, phakic IOLs implantation is less invasive and preserves accommodation in addition to the reduced risk of development of retinal detachment after surgery. Therefore, it is more appropriate than clear lens extraction for treating high myopia in young patients. There are three types of phakic IOLs: angle-supported anterior chamber lenses, iris fixated lenses and posterior chamber lenses. The angle-supported anterior chamber lens, such as the Baikoff or Nuvita lens [figure: 1 A \& B], can cause chronic compromise of the anterior-chamber angle, leading to glaucoma; pupil ovalization [2].

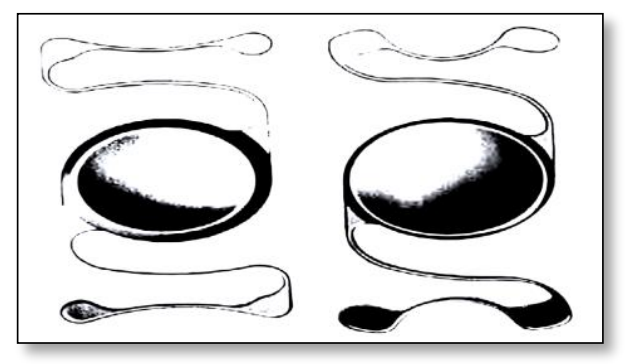

Figure [1]: [A] Baikoff lens and [B] Nuvita lens

The posterior chamber implantable contact lens, such as the STAAR lens, can induce cataract, because of contact with the crystalline lens; pigment dispersion and glaucoma. The Iris claw phakic intraocular lens [PIOL] is one option in the correction of high myopia. Iris-claw PIOL is placed in the anterior chamber and fixated to the anterior surface of the iris by a process known as enclavation [3].

The same iris-claw model has been available in other model known as the Artisan lens. There are two types, nonfoldable type 206 and foldable type 204, the type 206 has optic sizes [5.0 mm] and lens power from [-3.0 to $-23.0 \mathrm{D}]$ and type 204 has optic size [6.0 mm] and lens power from [3.0 to $-15.0 \mathrm{D}$ ] available to correct high myopia. The foldable phakic IOL model [Artiflex/Veriflex] has the advantage of being able to be implanted via a $3.2 \mathrm{~mm}$ incision, compared to the $6.2 \mathrm{~mm}$ incision required by the Verisyse or Artisan lens. The foldable phakic IOL model [Artiflex/Veriflex] was FDA approved and this lens is a convex-concave threepiece phakic IOL with a hydrophobic polysiloxane $6 \mathrm{~mm}$ optic and PMMA haptics [Figure $2 \mathrm{~A} \& \mathrm{~B}$ ] ${ }^{[2]}$.
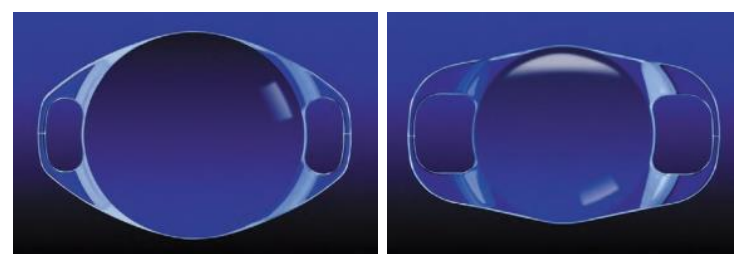

Figure [2]: [A] The iris-claw Artisan [Ophtec] / Verisyse [AMO] models [A] 204 [6.0 $\mathrm{mm}$ optic] and [B] 206 [5.0 mm optic]

Various incision techniques [e.g., corneal, limbal, or scleral tunnel incision] can be used usually a superior limbal incision was used. Depending on the diameter of the lens used $-5.0 \mathrm{~mm}$ or $6.0 \mathrm{~mm}$, the incision should be at least 5.2 $\mathrm{mm}$ or $6.2 \mathrm{~mm}$, respectively, to avoid difficulties with IOL insertion. The enclavation spots can be marked on the cornea at the beginning of the procedure. The 'claw' haptics were fixated to the iris by a process called enclavation, and specially designed bent needles were used. Two side-port incisions $1.0 \mathrm{~mm}$ at 10 and 2 o'clock positions were required for enclavation. The lens was implanted vertically through the incision, then rotated and centered in front of the pupil with the haptics at 3 and 9 o'clock positions. The anterior chamber was filled with cohesive viscoelastic material. It was recommended to use high-viscosity sodium hyaluronate to maintain working space in the anterior chamber. The viscoelastic was injected through one of the puncture incisions to create a deep anterior chamber ${ }^{[4]}$.

This is an alternative to other types of refractive surgery that involve ablating the corneal stroma. With the lack of corneal ablation, higher levels of myopia and astigmatism can be corrected in patients with inadequate corneal thickness. The study done by Chung, et al, found that the procedure was effective and provided safe short-term results [5]. Phakic intraocular lenses may be a preferred technique in high myopia due to preservation of accommodation. In addition to advantages of PIOL include preserved corneal architecture, and potential removability and reversibility. Phakic IOL has been shown to produce better visual outcomes than refractive lens exchange and is thought to offer better quality of vision than excimer laser surgery. Phakic IOL may also be more attractive than laser refractive procedures for high myopia because of more predictable outcomes and fast recovery ${ }^{[6]}$.

Reduction of corneal endothelial cell density could occur due to excessive wall shear stress arising from the altered flow patterns in the anterior chamber. Loss of pigment cells from the iris could also be due to excessive wall shear stress due to changes in the fluid dynamics of the anterior chamber. Secondary glaucoma is possibly caused by increasing the resistance to the flow of aqueous humor, either within the anterior chamber or at the outflow ${ }^{[7]}$. 


\section{THE AIM OF THE WORK}

The aim of this study is to assess the outcome of foldable and hard [PMMA] iris claw PIOL implantation as one of surgical procedures in the management of high myopic young patients.

\section{PATIENTS AND METHODS}

This is a prospective comparative study includes forty eyes [40 eyes] of twenty high myopic patients [20 pt.] with refraction range of $[-10.0 \mathrm{D}$ to $-25.0 \mathrm{D}]$ without or with cylinder not more than [-2.0 D], patient age was between 20 and 40 years and had myopia >-10.0 D that was stable for at least 2 years before surgery. The stability criteria included the absence of spherical equivalent variations of more than $>-0.50 \mathrm{D}$. The patients were divided to two groups $[\mathrm{A}]$ and [B], each group contains twenty [20] eyes, the first 20 eyes [group A] received a concave-convex foldable iris claw PIOL and the remaining 20 eyes [group B] received a biconcave optic hard PMMA iris claw PIOL. In both PIOL types, the total lens diameter was $8.5 \mathrm{~mm}$, with an optic diameter of 6 $\mathrm{mm}$ and $5 \mathrm{~mm}$. Thickness varied with refractive power, increasing with the negative power of the IOL. Uncorrected visual acuity [UCVA], best-corrected visual acuity [BCVA], spherical equivalent SE, the anterior chamber depth [ACD], endothelial cell count [ECC] and coefficient of variation [CV] in the sizes of endothelial cells before and after surgery were measured. Preoperative and postoperative outcome data were collected and statistical analysis were compared between tow groups. All patients were verbally informed about the procedure, its advantages and disadvantages.

A written informed consent was obtained from all patients before surgery. This study was started in January 2017 and the last visits of the patients were in December 2019. All operations and postoperative follow up of patients were done at Al-Azhar university hospitals in Damietta and Cairo cities.

Preoperative preparation: Topical antibiotic [gatifloxacin $0.3 \%$ ] were administered 4 times during the 24 hours before surgery. One hour before surgery, the pupil was constricted with $2 \%$ pilocarpine. The eyes with high risk peripheral retinal degenerations, argon laser prophylactic photocoagulation were performed.

Anesthesia: All operations will be done under general anesthesia because all patients are young and to avoid back pressure of local anesthesia and to avoid the mydriatic effect of local anesthesia.

Surgical Procedures: According to recommended technique, for unfoldable hard PMMA PIOL, $5.2 \mathrm{~mm}$ or for foldable PIOL $3.2 \mathrm{~mm}$ limbal incision was centered at 12 o'clock. Two vertical paracentesis directed toward the enclavation area were performed at $2 o^{\prime}$ clock and 10 o'clock. The pupil should be constricted to protect the crystalline lens from contact with the PIOL or the instruments during surgery. This can be achieved by instilling pilocarpine $1.0 \%$ preoperatively or injecting acetylcholine [Myochol] in the anterior chamber at the beginning of the procedure. The anterior chamber was filled with a cohesive ocular viscosurgical device [OVD] [sodium hyaluronate $1 \%$, Healon]. The phakic intraocular lens was inserted into the anterior chamber using a specially designed implantation device for Artiflex lens [Operaid Artiflex Implantation Spatula]. The IOL was introduced and rotated 90 degrees into a horizontal position. After positioning, the iris tissue was grasped and enclavated into the haptics at 3 and 9 o'clock with the aid of an Operaid Artiflex enclavation needle. The PIOL was fixated with an enclavation needle that has a bent shaft and a bent tip that pushes the iris into both claws. The needle was introduced through one paracentesis and holds the fold of the iris while the PIOL was slightly depressed with the implantation forceps so the claws will automatically grasp the iris and the same maneuver is performed through the other paracentesis. Both fixation of the iris claws and proper centration of the PIOL over the pupil should be checked before the next step, which was one of the main advantages of this PIOL style. A peripheral iridectomy was performed to prevent papillary block. Alternatively, a Neodymium-yttrium aluminum garnet [Nd:YAG] laser by [ZEISS-Visulas- YAG III] was used in some patients preoperatively to create one or two small peripheral iridotomies. The corneal wound was then sutured with five interrupted 10-0 nylon sutures. The viscoelastic agent was removed by manual irrigation, removing a cohesive OVD by irrigation from tow paracenteces wounds. Then sutures were selectively removed, depending on the patient's refractive and topographic astigmatism, beginning at week four and over a period of three months.

Postoperative medication: In both groups of patients, topical antibiotic [gatifloxacin 0.3\%] and prednisolone acetate [1\%] were administered 4 times daily postoperatively and were gradually tapered over 4 weeks.

Postoperative examination: A full ophthalmologic examination was performed in all patients, including an anterior segment using slit lamp and measurement of intraocular pressure using Airpuff tonometer [Topcon CT800]. Visual acuity was evaluated using Snellen characters projected at a distance of 6 meters. Spherical equivalent refraction was measured using Autorefractometer [Nidek] and subjective methods. Anterior chamber depth was 
determined using [ZEISS IOL Master 500], UBM by A/S OCT [Topcon- 3D OCT - 2000]. Retinal examination was done using indirect ophthalmoscope [Keelar]. Postoperative monitoring was conducted on the first day and one week, then after 1, 3 and 6 months. Data was recorded corresponding not only to complications observed at regularly scheduled follow up times, but also at any time during the study.

\section{RESULTS}

Preoperatively, the mean SE was [-18.0 $\pm 7.0 \mathrm{D}]$ ranging from [-10.0 to $-25.0 \mathrm{D}]$ without or with cylinder up to [-2.0 D] in both groups $[A] \&[B]$. Postoperatively, at 6 months, in group $[A]$ the mean SE was $-0.30 \pm 0.10 \mathrm{D}$ within $\pm 1.0 \mathrm{D}$ of emmetropia, where eighteen eyes [90\%] had no refractive error and two eyes [10\%] had the mean SE was $-0.50 \pm 0.50$ $D$ with a range of [-0.50 to $-1.0 \mathrm{D}]$. However, in group [B], the mean SE was $-0.50 \pm 0.50 \mathrm{D}$ within $\pm 1.00 \mathrm{D}$ of emmetropia, where eleven eyes [55\%] had no refractive error and nine eyes [45\%] had the mean SE was $[-0.50 \pm$ 0.50 ] with a range of -0.50 to $-1.0 \mathrm{D}$. The difference between preoperative and postoperative SE at 6 months were no a statistically significant in both groups $[p=0.060]$. The mean preoperative refractive cylinder was $-1.13 \pm 0.87$ in group $[\mathrm{A}]$ and was $-1.36 \pm 0.64$ in group $[\mathrm{B}]$. The mean postoperative cylinder at 6 months, it was $-0.31 \pm 0.10$ in group [A] where eighteen eyes [90\%] had no cylindrical refractive error and two eyes [10\%] had cylinder range of [0.50 to $-1.00 \mathrm{D}]$. However, in group [B] it was [-0.51 \pm 0.51$]$ where eleven eyes [55\%] had no cylindrical refractive error and nine eyes [45\%] had cylinder range of -0.50 to $-1.0 \mathrm{D}$. The difference between preoperative and postoperative cylinder at 6 months were no a statistically significant in both groups [figure 3].

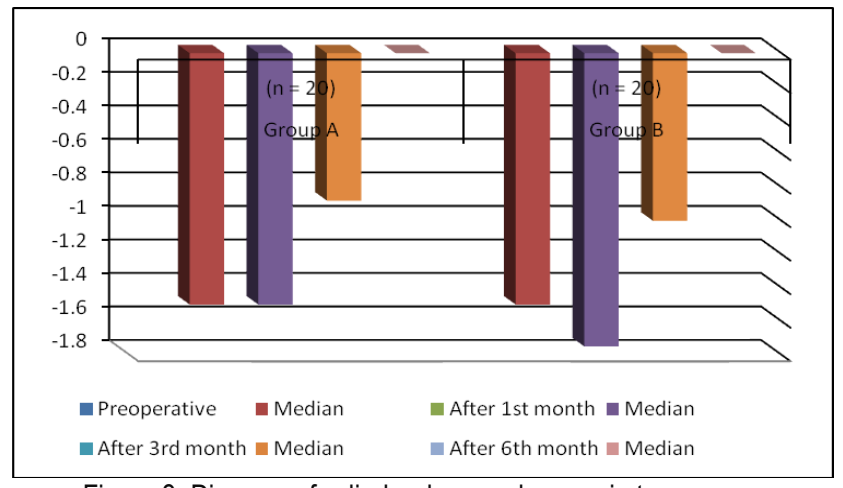

Figure 3: Diagram of cylinder degree changes in two groups

Preoperatively, UCVA [logMar] was [1.14 \pm 0.15$]$ in group $[A]$ and was $[1.57 \pm 0.33]$ in group $[B]$. Postoperatively UCVA [logMar] at 6 months, it was [0.12 \pm 0.15$]$ in group [A] and it was $[0.34 \pm 0.17]$ in group $[B]$. There was a statistically significant difference between preoperatively UCVA and postoperatively UCVA at 6 months were $[p<0.001]$ in both groups. And Preoperatively BCVA [logMar], was $0.14 \pm 0.15$ in group $[A]$ and $0.28 \pm 0.18$ in group $[B]$. Postoperatively BCVA [logMar] at 6 months was $0.11 \pm 0.14$ in group [A] and $0.27 \pm 0.17$ in group $[B]$. There was a statistically significant difference between preoperatively BCVA and postoperatively BCVA at 6 months [ $p \leq 0.002$ ] between the two groups throughout the follow up.

Endothelial cell count [ECC] and coefficient of variation [CV] in the sizes of endothelial cells were measured preoperatively and postoperatively at 6 months using Specular microscope [Topcon SP - IP 2000]. In group [A] with foldable PIOL, the preoperative endothelial cell count average was $3297.2 \pm 59.21 \mathrm{cells} / \mathrm{mm}^{2}$ but at 6 months postoperatively, the mean cell count was $3153 \pm 60.27$ cells $/ \mathrm{mm}^{2}$, with average decrease $144.2 \pm 18.13 \mathrm{celll} / \mathrm{mm}^{2}$ and percentage of decrease [4.37 $\pm 0.55 \%]$. However, in group $[\mathrm{B}]$ with hard [PMMA] PIOL, the preoperative endothelial cell count averaged was $3268.1 \pm 50.51$ cells $/ \mathrm{mm}^{2}$ but at 6 months postoperatively endothelial cell count averaged was $3122.8 \pm 45.95$ cells $/ \mathrm{mm}^{2}$, with average decrease $145.4 \pm 24.72$ cells $/ \mathrm{mm}^{2}$ and percentage of decrease [4.44 $\pm 0.72 \%$ ]. There was no a statistically significant difference between the two groups throughout the follow up [figure 4].

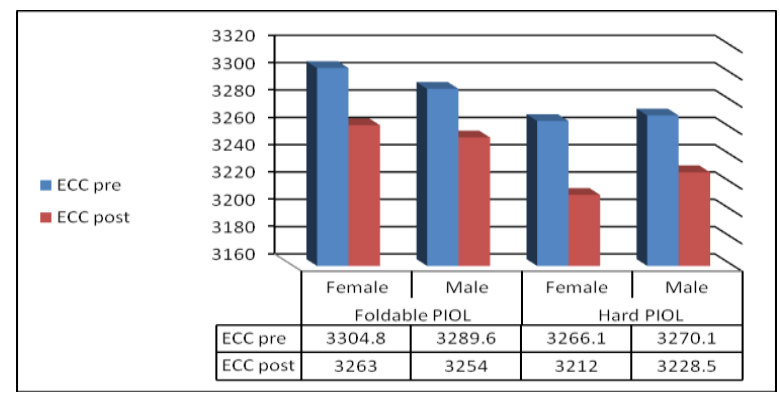

Figure [4]: Diagram of ECC changes in two groups

\section{DISCUSSION}

The results of this study were nearly or slightly less than the results reported by Nassiri et al. ${ }^{77}$, where, 55 eyes from 29 patients with a refractive error of $[-5$ to $-15 \mathrm{D}]$ were included in the study. The average age of patients was 24.9 years with a range of 20-39 years. Twenty [20] patients [75.9\%] were female and seven [7] patients [24.1\%] were male. Preoperatively the mean SE was $9.13 \pm 2.49 \mathrm{D}$. Postoperatively the mean SE was $0.36 \pm 0.44 \mathrm{D}$, [94\%] of the eyes had a refraction of $\pm 1 D$ from target refraction within 6 months after the surgery with a statistically significant change $[P<0.001]$. Also, the results of this study were nearly the results reported by Ozertürk et al. [4]; where 26 female and 14 male patients with a mean age of [28.7 \pm 7.1] years [range 19-46 years] were enrolled in the 
prospective study. Preoperatively the mean SE was -11.70 $\pm 3.77 \mathrm{D}$, the mean cylindrical refraction was $-1.25 \pm 1.11 \mathrm{D}$ and the mean SE was $-11.85 \pm 4.72 \mathrm{D}$. Postoperatively mean SE improved to $-0.73 \pm 0.82 \mathrm{D}$ after 1 month, and to $-0.94 \pm 0.78$ after 1 year, and to $-1.04 \pm 0.75 \mathrm{D}$ after 2 years. Postoperatively the mean SE at the first month in $69.4 \%$ of the eyes it was $\pm 0.5 \mathrm{D}$ of the desired refraction, while $84.7 \%$ and $90 \%$ of the eyes were within that range at the first and second years, respectively. And after 1 month, 1 year and 2 years, $90.2 \%, 92.3 \%$ and $88 \%$ of the eyes were within \pm 1.0 $\mathrm{D}$ of the desired refraction, respectively. And after 2 years, $96 \%$ of the eyes were within $2.0 \mathrm{D}$ of the desired refraction. No significant difference was found between mean SE values of the first month and the first year, and the mean SE values of the first and the second years $[P>0.05]$.

But the results of this study were nearly to or slightly better than the results were reported by Tahzib et al. $[8,9]$; in the Artiflex group, the mean SE was $-9.95 \pm 1.43$ D preoperatively and $-0.23 \pm 0.40 \mathrm{D}$ postoperatively. After 1 year, $85.7 \%$ of eyes were within $\pm 0.50 \mathrm{D}$ of the desired refraction. In the Artisan group, the mean preoperative SE was $-9.90 \pm 2.74 D$ preoperatively and $-0.21 \pm 0.45 \mathrm{D}$ postoperatively. After 1 year, $76.2 \%$ of eyes were within \pm 0.50 $\mathrm{D}$ of the desired refraction. There was no a significant difference between the two groups, where $74.2 \%$ of the eyes had a refraction of $\pm 1 \mathrm{D}$ from target refraction after 1 year.

In this study, the mean preoperative refractive cylinder was $-1.13 \pm 0.87 \mathrm{D}$ in group $[\mathrm{A}]$ and was $-1.36 \pm 0.64 \mathrm{D}$ in group $[B]$. The mean postoperative refractive cylinder changed in group $[A]$ after 1 month it was $-1.39 \pm 0.49 \mathrm{D}$, after 3 months it was $-1.08 \pm 0.44 \mathrm{D}$ and after 6 months it was $-0.31 \pm 0.10 \mathrm{D}$ respectively. But the mean postoperative refractive cylinder changes in group $[B]$ after 1 month it was $-1.80 \pm 1.08 \mathrm{D}$, after 3 months it was $-1.73 \pm 1.61 \mathrm{D}$ and after 6 months it was $0.51 \pm 0.51 \mathrm{D}$ respectively. The difference between preoperative and postoperative cylinder changes at 1, 3, 6 months were not statistically significant in both groups. The difference between preoperative and postoperative cylinder changes at 6 months were a statistically insignificant $[p=$ 0.060].

But the results of this study were different from results by Ozertürk et al. ${ }^{[4]}$; where they reported that all changes in refractive data were a statistically significant $[P<0.05]$. Regarding refractive cylinder, [83.8\%] eyes had less than $1.0 \mathrm{D}$ and $[61.3 \%]$ eyes had less than $[0.50 \mathrm{D}]$ of refractive cylinder postoperatively. $100 \%$ of eyes were within $1.0 \mathrm{D}$ of intended refraction and [63.8\%] of eyes were within [0.5 D] of intended refraction. Analysis of astigmatism revealed that mean surgically induced astigmatism was $0.17 \pm 0.81 \mathrm{D}$, mean difference vector was $0.57 \pm 0.39 \mathrm{D}$, mean absolute angle of error was $1.27 \pm 5.96 \mathrm{D}$, and mean arithmetic angle of error was $1.74 \pm 8.17$ six months after surgery. While we reported the difference between preoperative and postoperative cylinder changes at 1, 3, 6 months were no a statistically significant in both groups.

In this study Preoperative UCVA [LogMar] in group [A] was $1.14 \pm 0.15$ and in group $[B]$ was $1.57 \pm 0.33$. Postoperative UCVA [LogMar] after 1 month, in group $[A]$ it was $0.37 \pm 0.11$ and in group $[B]$ it was $0.53 \pm 0.08$. After 3 months, in group $[A]$ it was $0.31 \pm 0.10$ and in group $[B]$ it was $0.42 \pm 0.06$. After 6 months, in group $[A]$ it was $0.12 \pm 0.15$ and in group $[B]$ it was $0.34 \pm 0.17$. There was a statistically significant difference between preoperative UCVA and postoperative UCVA at 1,3 and 6 months were $[p<0.001]$ in both groups.

The results of this study were near to the results were reported by Nassiri et al. ${ }^{[7]}$ according to the results of examinations 6 months after lens implantation, visual acuity in both eyes was significantly improved, so that the mean UCVA before the surgery was $1.68 \pm 0.16$ [LogMAR], which improved to $0.10 \pm 0.22$ [LogMAR] after surgery with a statistically significant difference between preoperative UCVA and postoperative UCVA [p<0.001]. After the surgery, UCVA was $20 / 40$ or better in $93 \%$ of the eyes.

Also, the results of this study were nearly to the results by Ozertürk et al. ${ }^{[4]}$, where the mean preoperative UCVA was $1.36 \pm 0.41$ [LogMar] and improved to $0.28 \pm 0.27$ postoperatively, with statistical significant difference between preoperative UCVA and postoperative UCVA was $[P<0.001]$ after 2 years. UCVA was $20 / 40$ or better in $77 \%$, $73 \%$ and $84 \%$ of eyes after 1 month, 1 year and 2 years, respectively. The efficacy indexes the ratio of mean postoperative Snellen UCVA to the mean preoperative Snellen BCVA was 0.68 [ $n=72], 0.77[n=78]$ and 0.79 [n $=50]$ at the first month, and at the first and second years, respectively.

In this study, Mean Preoperative BCVA [LogMar], was $0.14 \pm 0.15$ in group $[A]$ and $0.28 \pm 0.18$ in group $[B]$. Postoperative BCVA [LogMar] after 1 month was $0.23 \pm 0.06$ in group $[A]$ and was $0.32 \pm 0.15$ in group [B]. After 3 months, BCVA was $0.11 \pm 0.14$ in group $[A]$ and $0.27 \pm 0.17$ in group $[B]$. After 6 months, BCVA was $0.11 \pm 0.14$ in group $[A]$ and $0.27 \pm 0.17$ in group $[B]$. There was a statistical significant difference between preoperative BCVA and postoperative BCVA at 1, 3 and 6 months [p $\leq 0.002$ ] between two groups throughout the follow up.

Also the results of this study were near to the results reported by Nassiri et al. ${ }^{[7]}$ According to the results of examinations, 6 months after lens implantation, visual acuity 
in both eyes was a significantly improved, so that the mean BCVA before surgery was $0.11 \pm 0.23$ [LogMAR], which improved to $0.06 \pm 0.19$ [LogMAR] postoperatively, with a statistically significant difference between preoperative BCVA and postoperative BCVA [ $p<0.001$ ], and BCVA was $20 / 30$ or better in $94 \%$ of the eyes.

Also, the results of this study were near to the results reported by Ozertürk et al. ${ }^{[4]}$, where the mean preoperative BCVA [LogMar] was $0.25 \pm 0.21$. The mean postoperative BSCVA at the first month was $0.17 \pm 0.16[P<0.05]$, at the first year was $0.16 \pm 0.17[P<0.05]$, at the second year was $0.15 \pm 0.18[P<0.05]$. At the end of the second year, BSCVA was decreased 2 or more lines in two eyes [2.5\%]. After 1 month, 1 year, and 2 years [51.3\%] [37 of 72 eyes], [58.9\%] [46 of 78 eyes] and [76.0\%] [38 of 50 eyes] gained 1 line or more of BCVA respectively. BCVA was 20/40 or better in [81\%], [75\%] and [82\%] of the eyes at the first month, and at the first and second years, respectively. The safety index [the ratio of mean postoperative Snellen BCVA to mean preoperative Snellen BCVA] was $1.03[n=72], 1.10$ $[n=78]$ and $1.12[n=50]$ after 1 month, 1 year and 2 years, respectively.

Also the results of this study were similar to the results reported by Tahzib et al. ${ }^{[8,9]}$, where in Artiflex group, the improvement of [LogMar] BCVA from preoperatively a range of [- 0.08 to 0.15$]$ to postoperatively a range of $[-0.18$ to $0.00]$ was a statistically significant $[p=0.001]$. No eye lost Snellen lines of BCVA. In Artisan group, the improvement of [LogMar] BCVA from preoperatively a range of [- 0.10 to $0.22]$ to postoperatively a range of [- 0.10 to 0.10$]$ was a statistically significant $[P=0.003]$. One eye [4.8\%] lost 1 or more Snellen lines of BCVA.

In this study, endothelial cell density and coefficient of variation [CV] in the sizes of endothelial cells were measured before surgery and postoperative at 1, 3 and 6 months. In group $[\mathrm{A}], 20$ eyes with foldable $\mathrm{PIOL}$, the preoperative endothelial cell count average $3297.2 \pm 59.21$ cells $/ \mathrm{mm}^{2}$ and 6 months' postoperative mean cell count was $3153 \pm 60.27$ cells $/ \mathrm{mm}^{2}$ with average decrease $144.2 \pm$ $18.13 \mathrm{cells} / \mathrm{mm}^{2}$ with percentage of decrease $[4.37 \pm$ $0.55 \%]$. However, in group [B], 20 eyes with hard [PMMA] $\mathrm{PIOL}$, the preoperative endothelial cell count averaged was $3268.1 \pm 50.51 \mathrm{cells} / \mathrm{mm}^{2}$ and 6 months' postoperative endothelial cell count averaged was $3122.8 \pm 45.95$ cells $/ \mathrm{mm}^{2}$ with average decrease $145.4 \pm 24.72 \mathrm{cells} / \mathrm{mm}^{2}$ with percentage of decrease [4.44 $\pm 0.72 \%]$.

The results of this study were similar to the results reported by Nassiri et al. [7] the mean corneal ECC of patients before surgery was $2803 \pm 339 \mathrm{cell} / \mathrm{s} / \mathrm{mm}^{2}$, which changed to $2744 \pm 369$ cells $/ \mathrm{mm}^{2}$ six months after surgery $[p=0.142]$. CV in the sizes of endothelial cells before the surgery was $[25.7 \% \pm 7.1 \%]$ and six months after surgery it was $[25.9 \% \pm 5.4 \%][p=0.857]$. The ECC before lens implantation was $2809 \pm 339$ cells $/ \mathrm{mm}^{2}$, which changed to $2744 \pm 369 \mathrm{cell} / \mathrm{mm}^{2}$ six months after surgery. The CV in the sizes of endothelial cells before surgery was [25.7\% $\pm 7.1 \%]$, which changed to $[25.9 \% \pm 5.4 \%]$ six months after surgery, showing no a statistically significant change.

The results of this study were near to results reported by Ozertürk et al. ${ }^{[4]}$, where the mean preoperative ECC was $3023 \pm 422 \mathrm{cells} / \mathrm{mm}^{2}$. One month after surgery, the mean ECC was $2944 \pm 434$ cells $/ \mathrm{mm}^{2}$. At the first and second year visits, the mean ECC was $2872 \pm 353 \mathrm{cell} / \mathrm{mm}^{2}$ and $2797 \pm 457$ cells $/ \mathrm{mm}^{2}$ respectively. The mean endothelial cell loss after 1 month, 1 year and 2 years was $2.6 \%$ [ $n=72$ ], $4.9 \%[n=78]$ and $7.4 \%[n=50]$, respectively.

But the results of this study were better than the results reported by Dick et al. [1]; they reported that the mean preoperative endothelial cell count was $2,774 \pm 271$ cells/ $\mathrm{mm}^{2}$; these values reached $2,693 \pm 327 \mathrm{cell} / \mathrm{s} / \mathrm{mm}^{2}$ at six months. The change in endothelial cell counts was [-0.3\%] $[P>0.05]$ They reported the intra-operative trauma was considered the main cause of early cell loss. Investigators had found an acceptable mean endothelial loss of [2.89.2\%] after 2 years following iris-claw phakic lens implantation. Similarly, endothelial cell loss after Veriflex implantation was confirmed in other studies involving similar anterior chamber foldable iris-fixated PIOLs.

Also the results of this study were near to the results reported by Rahimi, et al. [10], they reported the endothelial cell count loss postoperatively was not statistically significant [ANOVA $P=0.288$ ]. The mean density preoperatively was $2436 \pm 157 \mathrm{cell} / \mathrm{sm} \mathrm{mm}^{2}$, and postoperatively was $2328 \pm 132$ cells $/ \mathrm{mm}^{2}$ after three months.

Complications: In both groups of this study, there were no serious intra-operative complications. Elevated IOP was probably due to remnants of viscoelastic material behind the lens. All eyes regained normal IOP by the end of the first postoperative week. The elevated IOP in those eyes was due to pigment dispersion and anterior uveitis which was treated with topical corticosteroids. Along the course of 6 months' follow-up, there was no evidence of lens changes or opacification in tow groups, no reported retinal complications or persistent IOP elevation. However, two [2] eyes [10\%] in the foldable group and tow [2] eyes [10\%] in a hard PMMA group, pigment precipitates were observed on the lens optic in both groups, were persistent during the first month but without affecting visual acuity or IOP levels. Also, one eye [5\%] of the hard PMMA group [B] had traumatic dislocation of IOL after three months postoperative and 
reposition again was done without serious complication and vision improved just iris atrophy at site of enclevation du to traumatic traction of haptic to iris tissue during dislocation. And another one case of iris atrophy [5\%] and slight decentration in the same case with the foldable PIOL group [A] was reported due to manipulation during enclavation of PIOL but without affecting visual acuity.

We consider that the unique anterior convex and posterior concave shape of iris-claw IOL allows the aqueous to flow easily between the chambers and a properly implanted IOL has no effect on the iris-lens diaphragm. Although an iridotomy with YAG laser preoperatively or a surgically intervened iridectomy is strongly recommended, we have performed neither of them, especially in cases with deep AC. In this study, the follow-up ranging from 1 to 6 months, no a significant IOP elevation has been recorded. Still, IOP should be closely monitored in such cases. Similarly, the incidence of pupil distortion, elevated intraocular pressure and cataract formation following irisfixated PIOL were low. Also during follow up any tight stitches were affected on visual acuity due to astigmatic effect were removed after 3-4 weeks after surgery.

The results of this study were better than the results reported by Rahimi et al. [10]; they reported postoperative complications included only iritis. Severe anterior uveitis was observed in 10 eyes [45\%] during the second to $20^{\text {th }}$ day of operation of which 3 eyes had an inflammatory membrane with hypopyon. All patients responded well to topical and subconjuctival betamethasone and systemic prednisolone [1 $\mathrm{mg} / \mathrm{kg}]$ for 10 days and resolved completely.

In conclusion, phakic iris-claw IOL implantation is frequently used for highly myopic cases. The field of phakic IOLs has greatly progressed in recent years. The increased knowledge on the anterior segment anatomy and the availability of better imaging technologies along with improved IOL designs and materials and surgical techniques has led to higher success rates with these lenses. Compared to corneal refractive surgery, phakic IOLs favorably compete for the correction of high myopia, with increasing predictability, efficacy, safety, and quality of vision. Phakic IOLs are the most predictable and stable of the refractive methods for preserving the crystalline lens in high myopia. The predictability, efficacy, safety, and quality of vision of the foldable lens were evident within the first six months. The BCVA remained the same or improved in all the eyes. Twenty eyes [50\%] improved one or more lines of visual acuity. In this study, we found that PIOL is safe, efficient, and predictable modality for treatment of high myopia. Moreover, the implantation of PIOL offers patients, especially in cases of high myopia with poor contact lens tolerance or spectacles inconvenience, an important chance to improve their vision and subjective well-being.

\section{Financial and Non-Financial Relationships and Activities of Interest}

None to be declared

\section{REFERENCES}

1. Dick HB, Budo C, Malecaze F, Güell JL, Marinho AA, Nuijts RM, et al. Foldable Artiflex phakic intraocular lens for the correction of myopia: two-year follow-up results of a prospective European multicenter study. Ophthalmology. 2009 Apr;116[4]: 671-7. [DOI: 10.1016/ j.ophtha.2008.12.059].

2. Fechner PU, van der Heijde GL, Worst JG. The correction of myopia by lens implantation into phakic eyes. Am J Ophthalmol. 1989 Jun 15;107[6]:659-63. [DOI: 10.1016/0002-9394 [89]90264-x].

3. Coullet J, Guëll JL, Fournié P, Grandjean H, Gaytan J, Arné JL, Malecaze F. Iris-supported phakic lenses [rigid vs foldable version] for treating moderately high myopia: randomized paired eye comparison. Am J Ophthalmol. 2006 Dec; 142 [6]:909-16. [DOI: 10.1016/j.ajo.2006.07.021].

4. Ozertürk Y, Kubaloglu A, Sari ES, Koytak A, Capkin M, Akçay L, Evcili PS. Foldable iris-fixated phakic intraocular lens implantation for the correction of myopia: two years of follow-up. Indian J Ophthalmol. 2012;60[1]:23-8. [DOI: 10.4103/ 0301- 4738.91340].

5. Chung JK, Kim JK, Lee JB, Lee SJ. Iris-fixated phakic intraocular lens implantation after retinal detachment surgery: long-term clinical results. J Cataract Refract Surg. 2013 Oct; 39 [10]:1494-501. [DOI: 10.1016/j.jcrs.2013.04.037].

6. Pineda R $2^{\text {nd }}$, Chauhan T. Phakic Intraocular Lenses and their Special Indications. J Ophthalmic Vis Res. 2016 Oct-Dec;11[4]:422-428. [DOI: 10.4103/2008-322X.194140].

7. Nassiri N, Ghorbanhosseini S, Jafarzadehpur E, Kavousnezhad S, Nassiri N, Sheibani K. Visual acuity, endothelial cell density and polymegathism after iris-fixated lens implantation. Clin Ophthalmol. 2018 Mar 29; 12:601-605. [DOI: 10.2147/OPTH. S157501].

8. Tahzib NG, Nuijts RM, Wu WY, Budo CJ. Long-term study of Artisan phakic intraocular lens implantation for the correction of moderate to high myopia: ten-year follow-up results. Ophthalmology. 2007 Jun; 114 [6]: 1133-42. [DOI: 10.1016/ j.ophtha.2006.09.029].

9. Tahzib NG, MacRae SM, Yoon G, Berendschot TT, Eggink FA, Hendrikse F, Nuijts RM. Higher-order aberrations after implantation of iris-fixated rigid or foldable phakic intraocular lenses. J Cataract Refract Surg. 2008 Nov;34[11]:1913-20. [Doi: 10.1016/j.jcrs.2008. 07.014].

10. Rahimi F, Hashemian MN, Dehsarvi B, Alipour F, Rajabi MT. Irissupported Artisan phakic intraocular lenses for treatment of moderate to high myopia. Iran J Ophthalmology. 2008; 20[1]:37-41 

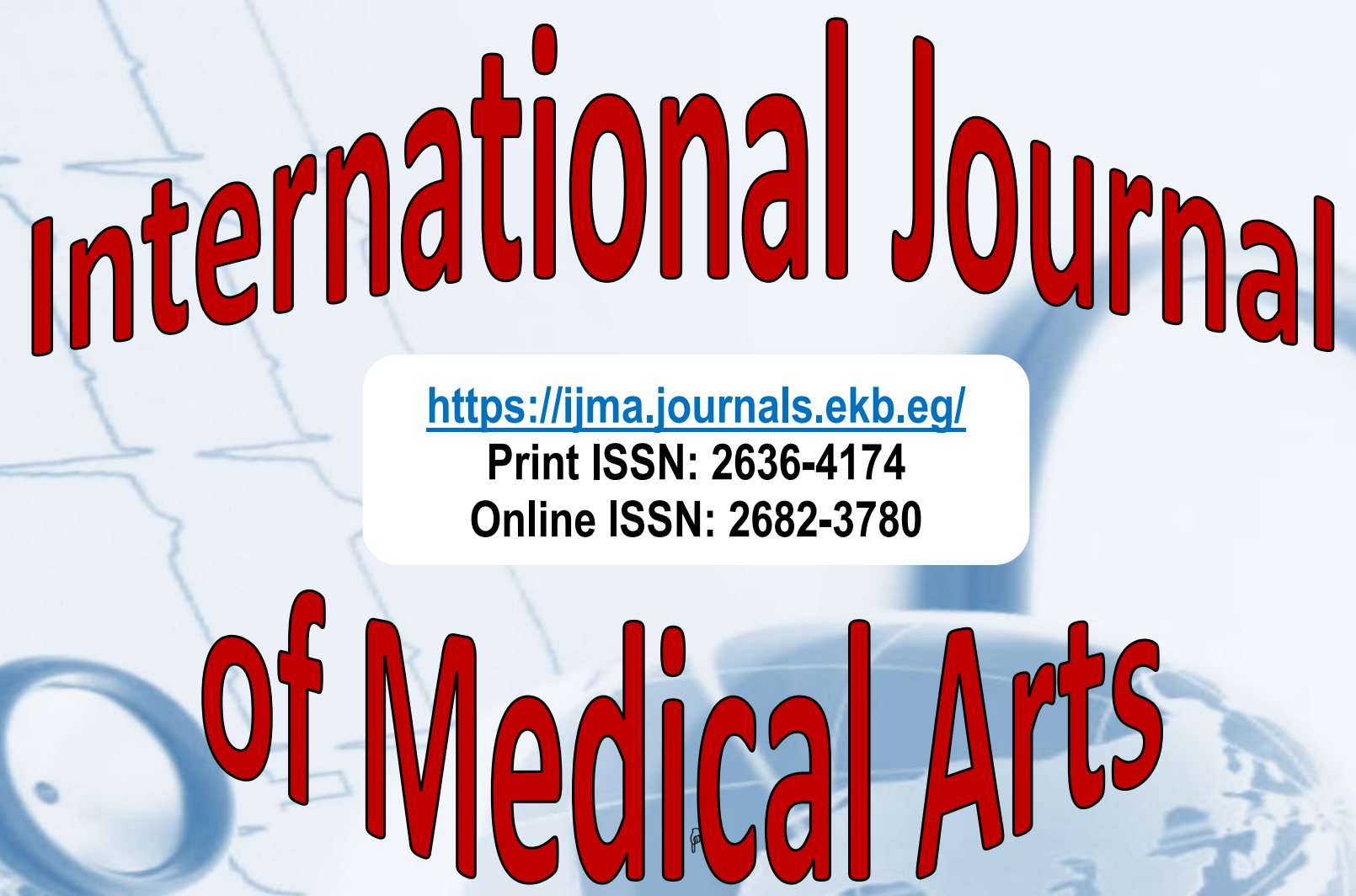